\title{
Reading Skills in Greek as a First Language and in French as a Foreign Language among Primary and Secondary School Children with Specific Reading Disorder
}

\author{
Georgia Andreou \\ Department of Special Education University of Thessaly \\ Argonafton \& Filellinon Street, Volos, GR-38221, Greece \\ E-mail: andreou@uth.gr \\ Vasiliki Tsela (Corresponding author) \\ Department of Special Education, University of Thessaly \\ Argonafton \& Filellinon Street, Volos, GR-38221, Greece \\ E-mail: vasso.tsela@gmail.com
}

Fotini Anastassiou (Corresponding author)

Department of Special Education, University of Thessaly

Argonafton \& Filellinon Street, Volos, GR-38221, Greece

E-mail: fanastassiou@gmail.com

Received: March 10, 2018 Accepted: April 13, 2018 Published: April 15, 2018

doi:10.5296/elr.v4i1.12820 URL: http://doi.org/10.5296/elr.v4i1.12820

\begin{abstract}
The aim of the present study is to investigate reading skills among primary and secondary school students with good reading skills with those of students with specific reading disorder, in Greek as a first language (L1) and in French as a foreign language (L2). Furthermore, a basic objective of the study is to investigate whether reading skills in Greek could predict
\end{abstract}


reading skills in French both for students with good reading skills and for students with specific reading disorder. The sample of the study consists of one hundred and eight $(\mathrm{N}=108)$ students with good reading skills and one hundred and eight $(\mathrm{N}=108)$ students with specific reading disorder who are assessed for decoding and fluency in reading, both in Greek and French languages. The results of the study revealed that students with specific reading disorder had lower performance than those with good reading skills, with a statistically significant difference, in all tasks of the French language. Furthermore, it was found that the deficits appeared in a specific task in one language were transferred analogically to the same task in the other language. Finally, there was a statistically significant relation between the tasks in both groups and in both languages.

Keywords: reading skills, Greek as a first language (L1), French as a foreign language (L2), specific reading disorder

\section{Introduction}

Reading is a complex cognitive process which demands the activation of cognitive and metalinguistic skills. For students with specific reading disorder, its development is not a normal procedure, causing children serious educational, psychological and social consequences. Research in foreign language learning by students with specific reading disorder is based on the hypothesis that there is a close relation between the students' skills in their first language and their ability to learn a second/foreign language (Cummins, 1996; Sparks, 2012). At the same time, researchers pursue the study of cross-language transfer of linguistic skills (Abu-Rabia \& Shakkour, 2014; Geva 2000) and the role of spelling characteristics of every language system in the course of acquiring literacy in various languages (Andreou, \& Baseki, 2012; Seymour, Aro \& Erskine, 2003; Ziegler \& Goswami, 2005).

\section{Connection between Mother Tongue and Foreign Language}

Research on foreign language learning has focused on the concept that there is a close relation between student's skills in their mother tongue and their ability to learn a foreign language. A lot of researchers (Meschyan \& Hernandez; 2002; Sparks, 1995; Sparks \& Ganschow, 1993; Sparks, Patton, Ganschow, Humbach,, \& Javorsky, 2008) have studied the link between mother tongue and a foreign language with respect to the language skills of students and suggested the viewpoint that successful foreign language learning could be based on someone's language skills in their mother tongue and that for foreign language learners with specific reading disorder various aspects of the function of the language could have a negative impact on their ability to learn a foreign language (Ganschow \& Sparks, 2001; Sparks, Patton, Ganschow, \& Humbach, 2009).

Cummins (1979) in Linguistic Interdependence Hypothesis as well as in the Threshold Hypothesis suggested that: a) both mother tongue and foreign language learning is based on common basic knowledge, b) success in learning a foreign language is mainly dependent on one's skills in the mother tongue, which developed before one's exposure to the foreign language and c) the level of achievement in the foreign language is determined by the level of 
achievement in the level in the mother tongue. Sparks and Ganschow suggested the Linguistic Coding Differences Hypothesis ( $L C D H)$ in order to explain the reasons why students show learning disabilities in foreign language learning and pinpoint the relation between learning the mother tongue and a foreign language (Sparks, 1995; Sparks \& Ganschow, 1993). In the Linguistic Coding Differences Hypothesis the researchers suggested that:

1) skills in mother tongue serve as a basis for foreign language learning,

2) both the mother tongue and a foreign language learning depend on basic mechanisms of language learning,

3) the level of skills in the components of the mother tongue - phonology, syntax, semantics, morphology - has an effect on foreign language learning ability,

4) problems in one language component, for instance in phonological processes, can have a negative effect on both languages learning, on the oral as well as the written forms,

5) students with learning disabilities in their mother tongue most probably will have lower competence in the foreign language.

In other studies (Durgunoglu, 2002; Geva, 2000) there has been established a strong relation between mother tongue and foreign language in a variety of languages. According to 'the central processing hypothesis (Geva \& Siegel, 2000), the acquisition of reading skills in a foreign language is dependent on the role of the basic cognitive skills, such as short-term memory and on the language skills, such as phonological (Durgunoglu, Nagy, \& Hancin-Bhatt, 1993). This hypothesis also posits that people with inadequate cognitive and language skills will face difficulties in acquiring basic reading skills, irrespective of the language and the writing mode involved and irrespective of whether it is the mother tongue or a foreign language (Geva \& Siegel, 2000). Similar studies showed that the frequency of appearance of serious reading problems does not differ between students who are learning different orthographic systems. Clinical studies on students with reading disorders showed that the difficulties in decoding were apparent both in the mother tongue and in the foreign language (Petrie \& Geva 1991 in Geva \& Siegel, 2000). These studies showed that, irrespective of the characteristics of the orthography involved, the students with decoding problems in their mother tongue develop decoding difficulties in the foreign language, as well. However, the type of reading mistakes observed among the students illustrates differences in the nature of orthographies.

Seymour, Aro and Erskine (2003), propounded a hypothesis for the classification of orthographic systems suggesting their classification in the double dimension, spelling complexity and orthographic depth. Katz and Frost (1992) formulated the hypothesis of orthographic depth, according to which shallow orthographic systems are based mainly on phonology during the reading process, that is, the high degree of transparency existing in graphophonemic correspondence can be exploited. On the other hand, deep orthographic systems are mainly based on morphology, that is, the reader is likely to use morphological information from the orthographic structure of the written words. The distinction between orthographic systems, as far as transparency is concerned, is considered significant because it 
can differentiate the course of literacy achievement in various countries. Specifically, while Ziegler et.al. (2010) were studying the role of phonological awareness in the reading skill for languages of different orthographic depth, they realized that language transparency was the most important factor for the influence degree on phonological process capacity in reading. Georgiou, Parrila \& Papadopoulos (2008) examined prediction patterns of word decoding and reading fluency of students in the first and second grades of elementary school in two orthographies of different transparency, Greek and English. The results showed that both the phonological and the orthographic processes contributed significantly in the reading ability. However, the significance of the prediction patterns was different in the two languages, especially as far as word decoding is concerned. The researchers suggested that the orthographic system in which the pupils are learning to read is an important factor which has to be taken into consideration during the generalization in various languages of reading development models.

\section{Aims of the Study}

The aim of the present study is to investigate reading skills among primary and secondary school students with good reading skills and compare them with those of students' with specific reading disorder, in Greek as a first language (L1) and in French as a foreign language (L2). Furthermore, a basic objective of the study is to investigate whether reading skills in Greek could predict reading skills in French both for students with good reading skills and for students with a specific reading disorder.

\section{Method}

This chapter will outline the features and ways of selecting survey participants, data collection tools, and the evaluation process. The survey was conducted within two school years 2012-2013 and 2013-2014 specifically from the end of February to the end of May. The Institute of Educational Policy (IEP) and the Ministry of Education have given permission to conduct this research.

\subsection{Subjects}

The sample of the study consisted of one hundred and eight $(\mathrm{N}=108)$ students with good reading skills and one hundred eight $(\mathrm{N}=108)$ students with specific reading disorder who were assessed for decoding and fluency in reading, both in Greek and French languages. Teachers, in order to set up a group of pupils with a specific reading disorder, completed the Learning Disabilities Screening for Teachers test (Padeliadu \& Sideridis, 2008). The test had questions about the reading profile of pupils with reading difficulties. It also took into account the existence of diagnosis by the Centers for Different Diagnosis, Diagnosis and Support of Specific Educational Needs (KEDDY) and the attendance in the Integration Classes in order to identify children with a specific reading disorder. Furthermore, this test on pupil's performance on Raven's Standard Progressive Matrices (Raven, 1960), which was sampled in both groups, checks optical perception for an initial assessment of mental capacity, to exclude cases of mentally retarded children. The group of students without reading difficulties comprised classmates of the group of children with specific reading disorder, of 
the same age and with high performance in reading, both according to the teachers' evaluation and to the mark they received during the A and B terms in the lesson of Modern Greek Language (Hauser-Cram, Sirin \& Stipek, 2003; Quatroche, Bean \& Hamilton, 2001).

\subsection{Sampling}

The students in the group with good reading skills were equaled individually with the group of students with specific reading disorder as far as age and mental level were concerned, as the latter was expressed by the IQ derived from the completion of Raven's Standard Matrices Test (Raven, 1960), adapted to Greek elementary school children's needs by Georgas (1971) and the adaptation to English speaking secondary school students' needs by Raven in 1979 (Raven, 2000). Finally, from the process of group formation, students whose mother tongue was not Greek were eliminated despite their excellent performance at school.

\subsection{Materials}

For the collection of the study data, four research tools were used, three of which were standardized and the fourth was a non-standardized criterion in the French language made for the purposes of the specific study. The three tools given to subjects of study covered three sectors namely Intelligence-Perception Ability, Reading Decoding and Fluency. Firstly, in the formation of the groups were used the criterion of Intelligence-Perception ability of Raven, (Raven, 1960) and the tool Learning Disabilities Screening for Teachers (Padeliadu \& Sideridis, 2008). The tool consists of six scales, reception and production of oral speech, reading and writing, reasoning and mathematics. Secondly, for the collection of data, the standardized tool for the Greek language Learning Disabilities Reading Inventory (Padeliadu $\&$ Antoniou, 2008) was used as well as a non-standardized tool for the French language made for the purposes of the specific study. The tools given to the students covered the fields of Reading Decoding and Fluency. The reading test (Padeliadu \& Antoniou, 2008) aims at the comprehensive assessment of the reading skills of students attending classes from third grade of Elementary school to third grade of Secondary school ( $8-15$ years of age) as well as the detection of students facing serious reading difficulties at the ages of compulsory education. Thirdly, the reading test for the French language is a non-standardized test edited according to the standardized reading test by Padeliadu \& Antoniou (2008) for the Greek language, in order to ensure the most accurate comparative study possible, in the two languages. According to the knowledge of the researcher, it doesn't exist neither in the Greek nor in the international literature a standardized test for the assessment of the specific skills for the French language as a foreign language concerning reading skills. So, for the creation of the questions, in the reading test on the French language, the following comparative criteria were taken into account: 


\section{Macrothink}

Table 1. Criteria for the creation of the reading test on the French language

1 Common European Framework of Reference for Languages (CEFR)

2 Cross Thematic Curriculum Framework along for the elementary schools with the Curriculum and Syllabus for French as for the secondary schools a foreign language:

3 The school textbook.

It was preferred that all subjects had been taught the same method.

4 The specific characteristics of the French Phonology language:

Morphology-Syntax

5 The structure and mentality of tools for the detection of reading difficulties in French as a mother tongue, used in international literature:

Batterie Analytique Du Langage Ecrit - BALE (Jacquier-Roux, Lequette, Pouget, Valdois, \& Zorman, 2010).

Batterie informatisée d'évaluation diagnostique des troubles spécifiques d'apprentissage de la lecture EVALEC (Sprenger-Charolles, Colé, Piquard-Kipffer, \& Leloup, 2010).

6 The French vocabulary frequency lists:

Lexique 3 (New, Pallier, Brysbaert, \& Ferrand, 2004)

Manulex Infra (Peereman, Lété, \& Sprenger-Charolles, 2007)

The formation of the tests was based on vocabulary factors such as the number of syllables, the frequency of words, the phonological similarity of words to other words, a factor known as the phonological proximity density of the word. Here are the tests of the reading criterion for Greek and French and the skills assessed for each test.

\subsection{Decoding}

In the first trial, the skill of decoding twenty four pseudo words, presented in three columns of eight words each (two cards) in increasing difficulty sequence, is assessed. Examples of pseudo words are "daire" and "fudre", which have no meaning but contain letter combinations commonly found in the French language (Padeliadu \& Antoniou, 2008; Sparks, et al., 2009; Sprenger-Charolles, Colé, Béchennec, \& Kipffer-Piquard, 2005). The researcher gives one (1) point for every correct answer and zero (0) points for every incorrect one.

In the second trial, the skill of decoding is assessed with fifty three real words resented in columns with eight words in each one of these three cards, one column of five words (one tab) in increasing difficulty sequence. The reading of these words is accomplished by graphophonemic correspondence or by orthographic recognition of the whole or part of the word. Examples of real words are "parle" and "chance" (Padeliadu \& Antoniou, 2008; Sparks, 
et al., 2009; Sprenger-Charolles, et al., 2005). The researcher gives one (1) point for every correct answer and zero (0) points for every incorrect one.

The third trial assesses the skill of distinction between 36 words, both pseudo and real, presented in threes, fours and fives in 2 cards - ( 20 real words). The student reads silently the words in every line and then reports which ones are real. The difficulty level increases as the number of words shown in every line increases. An example of such a line is "moli - ballon pefit". The pseudo words were made to correspond with the real ones in phonemes, syllables and digraphs (Content \& Radeau, 1988). This trial provides information about the type of reading strategies used by the student as well as about the role of semantics in reading accuracy (Padeliadu \& Antoniou, 2008). For every real word mentioned as real one the student takes one (1) point. For every pseudoword mentioned as real one he takes zero (0) points. After the completion of the test the empty spaces are filled with: one (1) point for every real word mentioned as real and zero(0) points for every real word not mentioned as such.

\subsection{Fluency}

The fourth trial assesses reading fluency, based on the correct words that the student decodes reading aloud a passage (210 to 519 syllables) shown on one card, in one minute. Because reading a passage does not require its comprehension but aims at the assessment of its precise and quick decoding, the passage includes both commonly used and rare words (Lefavrais, 1967; Padeliadu \& Antoniou, 2008). As Greek passage of reading fluency includes words with more syllables that the words in the French passage, the reading fluency count was based on syllables. During the test, the researcher circles the words wrongly read, those omitted or read by him. In the end, places a square bracket at the point where reading stopped and circles the corresponding number of syllables.

\subsection{Procedure}

The assessment procedure comprised three sessions, one with educators lasting 30 minutes on average and two with the subjects - students lasting two class-periods or one and a half hours on average, with short breaks on occasion. In the first session, during the collaboration with the educator in charge, the researcher initially handed an information letter about the aim and the procedure of the survey and, subsequently, if there was intention of co-operation, she handed the tool Learning Disabilities Screening for Teachers (Padeliadu \& Sideridis, 2008) and the list with the student demographics. After the filling-in of the Learning Disabilities Screening for Teachers and the demographics, the students' and their parents'/guardians' consent was ensured, and the date and time of the assessment was set. In the second session, the students who, according to the Learning Disabilities Screening for Teachers, had been characterized as likely to be have a specific learning disorder and the students with good reading ability were administered the perceptiveness and intelligence detection test of Raven - that is, Raven's Progressive Matrices (Raven, 1960). The second session of the research procedure, with the first assessment of the students, was concluded with the examination for the existence of the necessary criteria, on the part of the subjects, to participate in the survey. The students in both groups took part in the third session in which they were given the tools 
for the main study related to the assessment of reading skills both in Greek and in French. The assessment of all trials took place on an individual basis via a laptop in the elementary student's integration classroom or in another quiet room for the secondary school students; and lasted one and a half hours per student, on average. Following the administration instructions of Test-A as strictly as possible, an attempt was made to ensure for the students an environment free of distractions, well ventilated, well lit, quiet, secluded and comfortable. It was of major importance not to exist any noise both during the student's concentration period and during the observation of the student's reading performance by the researcher. Moreover, an attempt was made for a friendly atmosphere with the student to be created, so that the assessment procedure could be approached as a pleasant activity. Every session started with clear instructions and examples for every trial, so that the student would fully understand what he/she was asked to do, while during the assessment no feedback was given concerning their performance.

The validity of the questionnaires was examined for face validity and content validity based on feedback received by a pilot testing of a 40 student sample. The validity of the two tests (Greek and French), in the context of internal validity, was checked based on the values of Cronbach's index $\alpha$ (Spector, 1992). Cronbach's index $\alpha$ was categorized as follows: 0.00-0.25 = minimum to no validity, 0.26-0.49 = low, 0.50-0.69 = medium, 0.70- 0.89 = high and $0.90-1.00=$ excellent validity. The Greek test bears a validity index of $\alpha=0.70$, while the French $\alpha=0.76$. For the statistical analysis of data were estimated: central tendency indices (mean and intermediate values), dispersion indexes (minimum - maximum values, typical variations), accuracy indexes (typical errors), validity indexes (Cronbach's $\alpha$ ) and correlation coefficients (Pearson's $r$ ). For the above mentioned analysis the method ANOVA (Kirk, 1995) was applied. ANOVA's application estimated the comparison standard deviation for the statistical examination of differences between means. The comparison of the means was made according to the criterion of the Least Significant Difference (LSD), [Toothaker, 1993]) at a significance level $P<0.05$. The statistical analyses were done with the use of the software program SPSS v.15.0.

\section{Results}

The results of the study showed that students with specific reading disorder had lower performance than those with good reading skills, with a statistically significant difference, in all tasks of the French language. Furthermore, it was found that the deficits appeared in a specific task in one language were transferred analogically to the same task in the other language. Finally, there was a statistically significant relation between the tasks in both groups and in both languages. The results of the present study can be further used to create intervention programs which will help students with specific reading disorder to improve their reading skills in a foreign language. 
Table 2. Performance of students with GRA and SRD in Greek and French on the decoding axis

\begin{tabular}{|c|c|c|c|c|c|}
\hline & & Greek & & Frencl & \\
\hline Group & Class & M.V. & R.T. & M.V. & R.T. \\
\hline \multirow[t]{5}{*}{ GRA } & $5^{\text {st }}$ primary & 82,51 & 6,96 & 80,00 & 5,28 \\
\hline & $6^{\text {th }}$ primary & 82,89 & 6,16 & 81,99 & 5,27 \\
\hline & $1^{\text {st }}$ high school & 86,29 & 4,80 & 84,42 & 5,64 \\
\hline & $2^{\text {nd }}$ high school & 89,67 & 5,38 & 84,69 & 5,19 \\
\hline & $3^{\text {rd }}$ high school & 94,19 & 4,05 & 85,07 & 4,51 \\
\hline \multirow[t]{6}{*}{ SRD } & $5^{\text {th }}$ primary & 39,83 & 3,90 & 28,76 & 4,19 \\
\hline & $6^{\text {th }}$ primary & 40,79 & 3,85 & 29,20 & 4,05 \\
\hline & $1^{\text {st }}$ high school & 41,78 & 3,86 & 29,90 & 4,18 \\
\hline & $2^{\text {nd }}$ high school & 43,15 & 3,58 & 30,75 & 4,09 \\
\hline & $3^{\text {rd }}$ high school & 46,07 & 4,34 & 32,41 & 3,58 \\
\hline & $\mathrm{LSD}_{0,05}$ & 2,84 & & 2,84 & \\
\hline Total GRA & & 87,11 & 6,98 & 83,23 & 5,85 \\
\hline \multirow[t]{2}{*}{ Total SRD } & & 42,00 & 4,33 & 30,01 & 4,16 \\
\hline & $\mathrm{LSD}_{0,05}$ & 1,27 & & 1,27 & \\
\hline
\end{tabular}

GRA: Good Reading Ability, SRD: Specific Reading Disorder.

M.V.: Median Value, TD: typical deviation, LSD: Least Significant Difference $(P<0.05)$.

Table 2 presents the means of performances among students with good reading ability and the students with specific reading disorder for each language, both in the total of students in each group and separately in every class, on the axis of reading decoding. This test includes three trials: decoding of pseudo words, decoding of real words and discrimination between real and pseudo words. According to the data in Table 2, it is observed that the group of students with good reading ability outperformed the group of students with specific reading disorder on the axis of decoding of the reading test both in the Greek and in the French languages $(P<0.001$, $\mathrm{LSD}=1.27$ ). Also, according to the data of the Table 2, it is observed that on the axis of decoding, the scores of the group of students with good reading ability for the reading test in the Greek language were statistically significantly higher (LSD=1.27, $P<0.001)$ than the scores in the Reading Test in the French language. The same is observed for the group of students with specific reading disorder. 
Table 3. Performance of students with GRA and SRD in Greek and French on the reading fluency axis

\begin{tabular}{|c|c|c|c|c|c|}
\hline \multirow[b]{2}{*}{ Group } & \multirow[b]{2}{*}{ Class } & \multicolumn{2}{|l|}{ Greek } & \multicolumn{2}{|c|}{ French } \\
\hline & & MD & TD & MD & TD \\
\hline \multirow[t]{5}{*}{ GRA } & $5^{\text {st }}$ primary & 76,61 & 8,50 & 64,94 & 5,49 \\
\hline & $6^{\text {th }}$ primary & 83,18 & 9,57 & 73,53 & 5,44 \\
\hline & $1^{\text {st }}$ high school & 88,79 & 8,81 & 84,22 & 6,77 \\
\hline & $2^{\text {nd }}$ high school & 95,68 & 5,47 & 90,97 & 4,88 \\
\hline & $3^{\text {rd }}$ high school & 98,39 & 2,51 & 97,23 & 3,46 \\
\hline \multirow[t]{6}{*}{ SRD } & $5^{\text {th }}$ primary & 31,46 & 4,24 & 21,09 & 7,40 \\
\hline & $6^{\text {th }}$ primary & 39,07 & 6,41 & 21,84 & 3,89 \\
\hline & $1^{\text {st }}$ high school & 40,59 & 6,07 & 23,68 & 4,59 \\
\hline & $2^{\text {nd }}$ high school & 49,78 & 4,10 & 26,93 & 4,93 \\
\hline & $3^{\text {rd }}$ high school & 50,37 & 3,45 & 29,64 & 3,20 \\
\hline & $\mathrm{LSD}_{0,05}$ & 3,55 & & 3,55 & \\
\hline Total GRA & & 87,48 & 10,95 & 80,64 & 12,62 \\
\hline \multirow[t]{2}{*}{ Total SRD } & & 41,36 & 8,61 & 24,16 & 5,88 \\
\hline & $\mathrm{LSD}_{0,05}$ & 1,59 & & 1,59 & \\
\hline
\end{tabular}

GRA: Good Reading Ability, SRD: Specific Reading Disorder.

M.V.: Median Value, TD: typical deviation, LSD: Least Significant Difference $(P<0.05)$.

For the study of the correlation among all the skills between the Greek and the French, the correlation coefficient $r$ (Pearson's $r$ ) was estimated and assessed. For the students with good reading ability the test of decoding in the Greek language correlated strongly, positively and statistically significantly with the test of fluency in the French language $(r=0.873, P<0.001)$ and very strongly, positively and statistically significantly with the test of decoding in the French language $(r=0.727, P<0.001)$. Next, the test of fluency in the Greek language correlated very strongly, positively and statistically significantly with decoding $(r=0.716$, $P<0.001)$ and fluency $(r=0.802, P<0.001)$ in the French language. For the students with specific reading disorder the test of decoding in the Greek language correlated strongly, positively and statistically significantly with the tests of decoding and fluency in the French language $(r=0.555, r=0.470, P<0.001)$. Furthermore, the test of fluency in the Greek language correlated strongly, positively and statistically significantly with fluency $(r=0.540$, $P<0.001)$ and moderately, positively and statistically significantly with the test of decoding in the French language $(r=0.372, P<0.001)$. 
Table 4. Correlation of the skills in Greek and in French

\begin{tabular}{llll}
\hline Group & Tests Greek/ French & Decoding & Reading Fluency \\
\hline GRA & Decoding & $r=0,727$ & $r=0,873$ \\
& & $P<0,001^{*}$ & $P<0,001^{*}$ \\
& Reading Fluency & $r=0,716$ & $r=0,802$ \\
& & $P<0,001^{*}$ & $P<0,001^{*}$ \\
\hline SRD & Decoding & $r=0,555$ & $r=0,470$ \\
& & $P<0,001^{*}$ & $P<0,001^{*}$ \\
& Reading Fluency & $r=0,372$ & $r=0,540$ \\
& & $P<0,001^{*}$ & $P<0,001^{*}$ \\
\hline
\end{tabular}

GRA: Good Reading Ability, SRD: Specific Reading Disorder

*Statistically significant result.

\section{Discussion}

Our results generally revealed that students with specific reading disorder had lower performance than those with good reading skills, with a statistically significant difference, in all tasks of the French language. Furthermore, it was found that the deficiencies which appeared in a specific task in one and only language were transferred analogically to the same task in the other language. Finally, there was a statistically significant relation between the tasks in both groups and in both languages.

\subsection{Performances between Groups in Each Language}

The results showed that the group with specific reading disorder had a lower performance than the group with good reading ability in decoding and fluency both in the Greek and in the French languages with a statistically significant difference. According to the phonological processing deficit hypothesis, on the base of reading difficulties lies a deficit in phonological awareness. More specifically, the students with specific reading disorder seems to find it difficult to separate words in their components (syllables and phonemes) and combine the letters with the sounds (phthongs) they represent (Ramus \& Ahissar, 2012; Snowling, 2013). Also, it has been found that the phonological deficit has an effect on learning to read new phonological codes (Vellutino, Fletcher, Snowling \& Scanlon, 2004; Hulme \& Snowling, 2014).

In the present study, the very low scores of the students with specific reading disorder in the test of decoding and especially in the trial of reading pseudo words could be attributed to their limited phonological skills. This is true since decoding pseudo words is based on the phonological strategy of recognizing words and which constitutes a reliable criterion of graphophonemic correspondence by students (Nikolopoulos, Goulandris, Hulme, \& Snowling, 2006; Vellutino, et al., 2004). The low scores of students in the two reading tests, in Greek 
and French, showed that the students with specific reading disorder had great difficulty decoding high frequency words but with low graphophonemic correspondence, as well as in decoding low frequency words with high graphophonemic correspondence, which words the two reading tests were structured with. The first case of words demands the use of orthographic strategy for decoding, a process which is quite difficult for students with specific reading disorder, who are characterized by poor short term memory and slow automatized naming (Snowling, 2013). The second case of words demands the use of phonological strategy for decoding. As students with specific reading disorder are characterized by difficulties in phonological processing they find it especially difficult to decode low frequency words with high graphophonemic correspondence (Snowling, 2013).

As for the third trial in decoding, which required the distinction between real and pseudo words, the students with specific reading disorder encountered significant difficulty, as this trial requires the simultaneous use of the two reading strategies. Research has shown that the two reading processing routes do not develop independently, therefore the difficulties faced by the students with specific reading disorder in graphophonemic correspondence, and, as a result, in the phonological processing route, also affect the orthographic processing route in reading (Sprenger-Charolles, Colé, \& Serniclaes, 2006). On the other hand, in this trial, where the students are asked to decode concurrently real and pseudo words and chose the ones which are real, it is required the utilization of the meanings of the words, a procedure which seems to be very difficult for students with specific reading disorder. Limited optical processing, deficient phonological processing, limited short term memory and slow automatized naming are responsible for the disorders in semantics and vocabulary and explain the low scores in this trial (Vellutino, et al., 2004; Hulme \& Snowling, 2014).

As for decoding fluency, which was measured according to the number of correct syllables decode in one minute, significant differences were found between the two groups, since the students with specific reading disorder had lower performance than the students with good reading ability. Comparing the students' scores by grade, it was noticed that the performance of students with specific reading disorder in the Third Secondary School Grade was lower than that of the students with good reading ability in the Fifth Elementary School Grade. This result essentially features difficulty in reading fluency as one of the dominant characteristics in the manifestation of the disorder. These results are in agreement with other researches, such as Porpodas' (Porpodas, 2002; Porpodas, \& Palaiothodorou, 1999), who mentions that students with reading difficulties took significantly more time to decode real and pseudo words in comparison to fellow students who had normal performances, the sample of his researches, though, was of a younger age. Perfetti, Zhang, \& Berent, (1992), as well, points out decoding time as an important characteristic for the discrimination between students with specific reading disorder and good readers. Recent studies suggest that fluency assessment is a trial that detects more reliably than precision the existence of reading disorders for languages with shallow orthography, as is the Greek one (Protopapas \& Skaloumbakas, 2008). The very low scores of students with specific reading disorder in the Greek language, with transparent orthography, come in agreement with other studies which found out that problems in reading fluency cause the main difficulty in many transparent orthographies, which also 
have much fewer difficulties in phonological awareness.

\subsection{Performances of the Two Groups in the Greek and French Languages}

The results proved that the performance of both student groups was lower in decoding and fluency for French as a foreign language in comparison with the reading trial in Greek as mother tongue, with statistically significant difference. Despite the differences between the two writing systems, common basic language skills which affect reading in the mother tongue could also have an impact on reading in the foreign language. The present study provides data showing that the group of Greek students with specific reading disorder faced difficulties in learning French as a foreign language. These students have low performance in precision and fluency in both languages. The results of this study are consistent with the Linguistic Coding Differences Hypothesis, which suggests the existence of a common linguistic basis consisting of orthographic and phonological characteristics in order to explain language capacity. Difficulties in one or more of these characteristics could affect reading acquisition in a foreign language. Thus, the Greek students with specific reading disorder showed difficulties in learning French as a foreign language, which result from difficulties they face in the language processing of their mother tongue.

The significant differences between students with specific reading disorder and students with good reading skills in decoding and fluency of French as a foreign language are consistent with studies investigating performances of students with specific reading disorder in comparison with performances of students with good reading skills in a foreign language. According to the results of previous studies, (Ghonsooly \& Javadian, 2010; Helland \& Kaasa, 2005; Ho \& Fong, 2005), the performances of students with specific reading disorder were significantly lower than those of students with good reading skills in reading tests on the foreign language. Ho and Fong (2005), irrespective of the specific characteristics of the two orthographic system, the Chinese students without specific reading disorder scored better results than the students with specific reading disorder in all the tests on the foreign language.

The results of the study showed that the coexistence degree of reading difficulties in the two languages was high, despite the fact that the two languages have different characteristics. It seems that the Greek students with specific reading disorder have high risk degree of reading difficulty in learning a foreign language. The severity of reading difficulties of the students in the mother tongue is reflected by the severity of reading difficulties in the foreign language. These students perform inadequately in reading tests on both languages. The results of this study are consistent with the Linguistic Coding Differences Hypothesis, which surmises that the students' skills levels in their mother tongue are analogous to their levels of performance in the foreign language (Sparks \& Ganschow, 1993, 2007; Sparks, 2012).

The findings also support Carroll's (1973) postulation who suggested that competency in the foreign language is a remaining of competency in the mother tongue, and Cummins's (1979), who suggested that success in the foreign language mainly depends on one's skills in the mother tongue. The description of skills of the two groups in the mother tongue was consistent with their level of performance in the foreign language. That is, the students with good reading skills had a high performance in both languages whereas the students with 
specific reading disorder had low performances both in the mother tongue and in the foreign language.

These results agree with the finding of Sparks and Ganschow (Sparks \& Ganschow, 1993, 2007; Sparks 2012), who maintain that performance in the foreign language is closely connected with the level of students' performance in the mother tongue. These researchers claim that mother language skills are used as a basis for the performance in the foreign language (Sparks, 1995, Sparks \& Ganschow, 1993, 2007; Sparks et al., 2009). The results also tally with Linguistic Threshold Hypothesis (Cummins, 1979) which maintains that the level of performance in the foreign language is determined by the level of performance in the mother tongue. The results also agree with other studies which have repeatedly established that skills in the mother tongue are closely connected with the oral and written performance of students in L2 (Sparks, et al., 2008, 2009).

From the differences in performance between the Greek and the French languages, the results showed that the students with good reading skills had a lower performance in French in comparison to Greek, while the students with specific reading disorder had disproportionately much lower performance in the French language compared to the students with good reading skills. This far lower performance of students with reading disorder in French can be explained by the Orthographic Depth Hypothesis (Katz \& Frost, 1992 in Porpodas, 2002). According to Seymour et. al (2003) classification, Greek and French have simple orthographic structures, while, as far as graphophonemic correspondence is concerned, Greek belong to a rather shallow orthographic system whereas French to a rather deep orthographic one. Greek, as a transparent language was considered likely to cause less difficulty to the students with specific reading disorder, since it is characterized by a regular one by one $(1: 1)$ Phoneme-Grapheme Correspondence. Moreover, in Greek as a mother tongue, graphophonemic correspondences are systematically taught to students from the moment they begin to learn how to read (Goswami, 2002), while no teaching on a graphophonemc level takes place when it comes to a foreign language. On the other hand, the French language is characterized by low transparency of graphophonemic correspondence and, as a result, the reader is based more on morphology, that is, he is likely to use morphological information from the orthographic structure of written words. From these results, it was concluded that transparency degree of the Greek and French languages affected and determined the performances of students in both groups. As for the test of decoding pseudo words, the students with specific reading disorder had worse scores than in the test of decoding real words in the French language than in the Greek language. This result comes in agreement with the research made by Seymour et. al. (2003) according to which Greek speaking students are superior to the French speaking ones, as far as precision and speed in reading pseudo words is concerned. These finding reveals that reading in Greek is acquired more easily than reading in French.

Furthermore, from the fluency trial, the results showed that the difference in performance between Greek and French for the group of students with specific reading disorder is much greater than the difference for the group with good reading skills in the specific trial and even greater than the difference in the decoding trial. That is, the students with reading disorder have better performance in decoding precision than in reading speed in the Greek language. 
This result agrees with studies which showed that inadequacies in transparent orthographic systems seem to affect not so much the correctness of reading or writing process, as the time it takes to process these skills (Wimmer \& Landerl, 1997). What distinguishes students with specific reading disorder is mainly an unusually slow reading speed, while they can read with relative precision. Similar were the conclusion reached by Ziegler et al. (2010) and by Georgiou, et al. (2008), who suggested that the orthographic system in which children learn to read is a significant factor that has to be taken into account in the generalization of reading development models for many languages.

\subsection{Projection of Reading Skills on a Foreign Language from the Mother Tongue}

The results of the research showed that for the group of students with good reading ability the skills in decoding and fluency could constitute predictive indicators for the same skills in the French language. For the students with specific reading disorder the skills in decoding and fluency in the Greek language can project the same skills in the French language. Consequently, the results showed that Greek students with specific reading disorder will face difficulties in learning French as a foreign language, which originate from difficulties in language processing in the mother tongue as well as from the inter-linguistic transfer of inadequacies from the one language to the other, which subsequently affect foreign language learning. On the other hand, the student with good reading skills in their mother tongue showed the same performance in the foreign language. These finding come to add to the existing knowledge on inter-linguistic transfer from the mother tongue to a foreign language and provide further proof of inter-linguistic transfer of inadequacies in cognitive skills that relate to reading between the two languages.

Given that Greek and French are two alphabetic languages, the precise and fluent decoding are significant for reading acquisition in the two languages. The correspondence noticed in the decoding and fluency trials between the Greek and the French languages shows that for students who are learning a foreign language, structural similarities between mother tongue and foreign language can facilitate reading decoding acquisition in the foreign language. On the other hand, many surveys have shown phonological awareness is closely linked to the development of reading decoding and fluency and serves as a significant predictive indicator of subsequent reading skills (Chiappe, Siegel, \& Gottardo, 2002; Geva \& Siegel, 2000; Lipka, Siegel, \& Vukovic, 2005). Also, phonological awareness constitutes a linguistic skill that can be transferred between languages and which can be used as an important predictive factor for the reading skill not only for the mother tongue but also for the foreign language (Chiang \& Rvachew, 2007; Laurent \& Martiont, 2010; Sun-Alperin \& Wang, 2009). Consequently, the correlation noticed in the trial of decoding and the trial of fluency between Greek and French and which can explain that the transfer of decoding and fluency skills between the two languages is possible, agrees with surveys that show the inter-linguistic transfer of phonological skill, given the fact that on the base of reading decoding and fluency skills lies the skill of phonological awareness.

The results of the present research, concerning the correlation and inter-linguistic transfer of the decoding and fluency skills from the Greek, a shallow orthography, to French, a deeper 


\section{MInstitute Macrothink $_{\text {Int }}$}

orthography, agree with the findings of Wade-Woolley \& Geva (2000), who noticed the transfer of phonological skills between Arabic (a shallow orthography) and English (a deep orthography) and found a significant correspondence between phonological awareness in Arabic and reading acquisition in English. Moreover, the researchers suggested that phonological awareness was a good predictive indicator of reading acquisition in both languages. Based on these findings Woolley \& Geva (2000) suggested that a number of phonological aspects which do not relate to a specific language can be transferred from one language to another. The above mentioned finding supports the findings of the present study that the skills of decoding and fluency are transferred from the mother tongue to the foreign language and, moreover, these skills in Greek as a mother tongue can constitute predictive indicators for the skills of decoding and fluency in French as a foreign language.

Similar finding were revealed between a shallow orthography (Italian, Portuguese, German and Spanish) and English which is a deep orthography (D' Angiulli, Siegel, \& Serra, 2001; da Fontoura \& Siegel, 1995; Mann \& Wimmer, 2002; Sun-Alperin \& Wang, 2009). As for French as a foreign language, Chiang and Rvachew (2007) showed the possibility of transfer of phonological awareness from the English language, a deep orthography, to the French, a shallow orthography, and therefore, the transfer of the decoding skill from the one language to the other. However, the latest research showed that irrespective of the orthographic depth of languages there can be inter-linguistic a transfer of the decoding skill from the mother tongue to the foreign language. These facts verify the results of the present study, which showed that the skills of reading decoding and fluency are possible to be transferred from the Greek as a mother tongue to the French as a foreign language.

It is noteworthy that the strong correlation of reading decoding and fluency between the two languages was noticed in both groups, that is, in both the group with good reading skills and the group with specific reading disorder. These findings show that the performance level of reading decoding and fluency in the mother tongue can predict the performance level of the same skills in the foreign language. That is, the students with good performance in the skills of decoding and fluency in their mother tongue will have good performance in the same skills in the foreign language. Similarly, the students with low performance in the skills of decoding and fluency will have low performance in the same skills in the foreign language. Consequently, the skills of decoding and fluency in the mother tongue can be predictive indicators of the students' performance in the same skills in the foreign language. These results agree with and support the Linguistic Interdependence Hypothesis (Cummins, 1979, 1996) according to which there is a significant interdependence relationship between mother tongue and foreign language, as foreign language acquisition is significantly affected by the development degree of the mother tongue. Cummins maintains that, despite the different superficial characteristics of two languages, the interdependence relationship between them renders the transfer of cognitive skills related to written speech possible, from the one language to the other. Moreover, Cummins $(1979,1996)$ suggested the Threshold Hypothesis according to which the proficiency level in the foreign language is coordinated by the level of achievement in the mother tongue; therefore, an inadequacy in the one language will manifest itself in the other language, as well. In the same way, Sparks and Ganschow (Ganschow \& 
Sparks, 2001; Sparks, 2006, 2012), maintained that the skills in mother tongue serve as a basis for foreign language learning, that is, both mother tongue and foreign language learning depends on basic language learning mechanisms. Also, the researchers showed that the level of the mother tongue skills in the language components - phonology, syntax, semantics, morphology - affect foreign language learning competency, therefore, problems with one, at least, of these language components can have a negative effect on both languages learning, on the oral as well as the written aspect of them. Consequently, students with specific reading disorder in their mother tongue most probably will manifest the same disorder in the foreign language.

The transparency of graphophonemic correspondences and the structure of syllable of the two languages can be factors which determine the existence or not of correlation between the languages as far as accuracy and fluency are concerned. As a result, Greek can constitute a better basis for skills transfer into French. The findings of the present survey, together with other surveys, show that possible factors determining the inter-linguistic relationship of literacy skills are the alphabetic characteristics of the languages learned.

\section{Conclusion}

In conclusion, the data of the present survey support and agree with the above mentioned hypotheses, since they revealed that the strong correlation of decoding and fluency skills between Greek as a mother tongue and French as a foreign language both for students with good reading skills and for students with specific reading disorder can explain transfer of the specific skills from the one language into the other, but it can also support the predictive property of the level in reading decoding and fluency from the mother tongue into the foreign language both for students with good reading skills and for students with specific reading disorder.

\section{References}

Abu-Rabia, S., \& Shakkour, W. (2014). Cognitive Retroactive Transfer (CRT) of Language Skills among Trilingual Arabic Hebrew and English Learners. Open Journal of Modern Linguistics, 4, 1-20. https://doi.org/10.4236/ojml.2014.41001

Andreou, G., \& Baseki, J. (2012). Phonological and Spelling Mistakes among Dyslexic and Non-Dyslexic Children Learning Two Different Languages: Greek vs English. Psychology, 3, 595-600. https://doi.org/10.4236/psych.2012.38089

Carroll, JB. (1973). Implications of aptitude test research and psycholinguistic theory for foreign language learning. International Journal of PsychoLinguistics, 2, 5-14.

Chiang, P., \& Rvachew, S. (2007). English-French Bilingual Children's Phonological Awareness and Vocabulary Skills. Canadian Journal of Applied Linguistics, 10, 293-308.

Chiappe, P., Siegel, L., \& Gottardo, A. (2002). Reading-Related Skills of Kindergartners from Diverse Linguistic Backgrounds. Applied Psycholinguistics, 23, 95-116. https://doi.org/10.1017/S014271640200005X 
Common European Framework of Reference for Languages: Learning, Teaching, Assessment. (2007). Strasbourg: Language Policy Division.

Content, A. Radeau, M. (1988). Données statistiques sur la structure orthographique du français. C. P. C.: Cahiers de Psychologie Cognitive. European Bulletin of Cognitive Psychology, 8, 399-404.

Cummins, J. (1979). Linguistic Interdependence and the Educational Development of Bilingual Children. Review of Educational Research, 49, 222-251. https://doi.org/10.3102/00346543049002222

Cummins, J. (1996). Negotiating identities: Education for empowerment in a diverse society. Ontario, CA: CABE.

D'Angiulli, A., Siegel, L. S., \& Serra, E. (2001). The Development of Reading in English and Italian in Bilingual Children. Applied Psycholinguistics, 22, 479-507. https://doi.org/10.1017/S0142716401004015

da Fontoura, H. A., \& Siegel, L. S. (1995). Reading, Syntactic, and Working Memory Skills of Bilingual Portuguese-English Canadian Children. Reading and Writing: An Interdisciplinary Journal, 7, 139-153. https://doi.org/10.1007/BF01026951

Durgunoglu, A. Y. (2002). Cross-Linguistic Transfer in Literacy Development and Implications for Language Learners. Annals of Dyslexia, 52, 189-204. https://doi.org/10.1007/s11881-002-0012-y

Durgunoğlu, A. Y., Nagy, W. E., \& Hancin-Bhatt, B. J. (1993). Cross language transfer of phonological awareness. Journal of Educational Psychology, 85, 453-465. https://doi.org/10.1037/0022-0663.85.3.453

Ganschow, L., \& Sparks, R. (2001). Learning difficulties and foreign language learning: A review of research and instruction. Language Teaching, 34(2), 79-98. https://doi.org/10.1017/S0261444800015895

Georgas, J. (1971). Georgas I.Q. test for children. Athens: Kedros Publications.

Georgiou, G. K., Parrila, R., \& Papadopoulos, T. C. (2008). Predictors of word decoding and reading fluency across languages varying in orthographic consistency. Journal of Educational Psychology, 100(3), 566-580. https://doi.org/10.1037/0022-0663.100.3.566

Geva, E. (2000). Issues in the assessment of reading disabilities in L2 children-Beliefs and research $\quad$ evidence. Dyslexia, $\quad 6, \quad 13-28$. https://doi.org/10.1002/(SICI)1099-0909(200001/03)6:1\%3C13::AID-DYS155\%3E3.0.CO;2 $-6$

Geva, E., \& Siegel, L. (2000). Orthographic and Cognitive Factors in the Concurrent Development of Basic Reading Skills in Two Languages. Reading and Writing: An Interdisciplinary Journal, 12, 1-30. https://doi.org/10.1023/A:1008017710115

Ghonsooly, B., Javadian, M. (2010). An Examination of Developmental Dyslexia among 
Iranian EFL Second Graders. International Journal of Language Studies, 4(4), 89-112.

Goswami, U. (2002). Phonology, Reading Development, and Dyslexia: A Cross-linguistic Perspective. Annals of Dyslexia, 52, 141-163. https://doi.org/10.1007/s11881-002-0010-0

Hauser-Cram, P., Sirin, S. R., \& Stipek, D. (2003). When Teachers' and Parents' Values Differ: Teachers' Ratings of Academic Competence in Children from Low-Income Families. Journal of Educational Psychology, 95(4), 813-820. https://doi.org/10.1037/0022-0663.95.4.813

Helland, T., \& Kaasa, R. (2005). Dyslexia in English as a second language. Dyslexia 11, 41-60. https://doi.org/10.1002/dys.286

Ho, C.S-H., \& Fong, K-M. (2005). Do Chinese dyslexic children have difficulties learning English as a second language? Journal of Psycholinguistic Research, 34(6), 603-618.

Hulme, C., \& Snowling, MJ. (2014). The interface between spoken and written language: developmental disorders. Phil. Trans. R. Soc, 369, 20120395.

Jacquier-Roux, M., Lequette, C., Pouget, G., Valdois, S., \& Zorman, M. (2010). Batterie Analytique Du Langage Ecrit (Bale). UMPF Grenoble Cognisciences.

Katz, L., \& Frost, L. (1992). Reading in Different Orthographies: The Orthographic Depth Hypothesis. In R. Frost, \& L. Katz (Eds.), Orthography, Phonology Morphology, and Meaning (pp. 67-84). Amsterdam: Elsevier.

Kirk, R. (1995). Experimental Design: Procedures for the Behavioral Sciences. Pacific Grove: Brooks/Cole Publishing Company.

Laurent, A., \& Martinot, C. (2010). Bilingualism and Phonological Awareness: The Case of Bilingual (French-Occitan) Children. Reading and Writing, 23, 435-452. https://doi.org/10.1007/s11145-009-9209-3

Lefavrais, P. (1967). Test de l'Alouette. Paris: Les Editions du Centre de Psychologie Appliquée (ECPA).

Lipka, O., Siegel, L. S., \& Vukovic, R. (2005). The Literacy Skills of English Language Learners in Canada. Learning Disabilities Research \& Practice, 20, 39-49. https://doi.org/10.1111/j.1540-5826.2005.00119.x

Mann, V., \& Wimmer, H. (2002). Phoneme awareness and pathways into literacy: A comparison of German and American children. Reading and Writing: An Interdisciplinary Journal. 2002; 15(7-8), 653-682. https://doi.org/10.1023/A:1020984704781

Meschyan, G., \& Hernandez, A. (2002). Is native-language decoding skill related to second-language learning? Journal of Educational Psychology, 94(1), 14-22.

New, B., Pallier, C., Brysbaert, M., Ferrand, L. (2004). Lexique 2: A New French Lexical Database. Behavior Research Methods, Instruments, \& Computers, 36(3), 516-524. https://doi.org/10.3758/BF03195598 
Nikolopoulos, D., Goulandris, N., Hulme, C., \& Snowling, M.J. (2006). The cognitive bases of learning to read and spell in Greek: Evidence from a longitudinal study. Journal of Experimental Child Psychology, 94(1), 1-17. https://doi.org/10.1016/j.jecp.2005.11.006

Padeliadu, S., \& Antoniou, F. (2008). Learning Disabilities Reading Inventory. Athens: YPEPTH: EPEAEK.

Padeliadu, S., \& Sideridis, G. D. (2008). Learning Disabilities Screening for Teachers. Athens: YPEPTH: EPEAEK.

Peereman, R., Lété, B., \& Sprenger-Charolles, L. (2007). Manulex-Infra: Distributional characteristics of grapheme-phoneme mappings, infra-lexical and lexical units in child-directed written material. Behavior Research Methods, 39, 579-589. https://doi.org/10.3758/BF03193029

Perfetti, C. A., Zhang, S., \& Berent, I. (1992). Reading in English and Chinese: Evidence for a "universal" phonological principle. In R. Frost \& L. Katz (Eds.), Orthography, phonology, morphology and meaning (pp. 227-248). Amsterdam: North-Holland.

Porpodas, K. D. (2002). Reading. Patras.

Porpodas, C., \& Palaiothodorou, A. (1999). A training study on phonological awareness and its effect on learning to read and spell the Greek language. Paper presented at the European Conference on Developmental Psychology, Spetses, Greece, 2-5/9/1999.

Protopapas, A., \& Skaloubakas, C. (2008). Assessment of reading fluency for the detection of reading difficulties. Psychology, 15(3), 267-289.

Quatroche, D. J., Bean, R. M., \& Hamilton, R. L. (2001). The role of the reading specialist: A review of research. The Reading Teacher, 55(3), 282-294.

Raven J. C. (1960). Guide to the Standard Progressive Matrices. London, England: HK Lewis.

Raven, J. (2000). The Raven's Progressive Matrices: Change and Stability over Culture and Time. Cognitive Psychology, 41, 1-48. https://doi.org/10.1006/cogp.1999.0735

Ramus, F., \& Ahissar, M. (2012). Developmental dyslexia: the difficulties of interpreting poor performance, and the importance of normal performance. Cognitive neuropsychology, 29(1-2), 104-22. https://doi.org/10.1080/02643294.2012.677420

Seymour, P. H. K., Aro, M., \& Erskine, J. M. (2003). Foundation literacy acquisition in European orthographies. British Journal of Psychology, 94, 143-174. https://doi.org/10.1348/000712603321661859

Snowling, M.J. (2013). Early identification and interventions for dyslexia: a contemporary view. Journal of Research in Special Educational Needs: JORSEN, 13(1), 7-14. https://doi.org/10.1111/j.1471-3802.2012.01262.x

Sparks, R. (1995). Examining the linguistic coding differences hypothesis to explain 
individual differences in foreign language learning. Annals of Dyslexia, 45, 187-214. https://doi.org/10.1007/BF02648218

Sparks, R. (2006). Is there a disability for learning a foreign language? Journal of Learning Disabilities, 39, 544-557.

Sparks, R. (2012). Individual differences in L2 learning and long-term L1-L2 relationships [Supplement]. Language Learning, 62, https://doi.org/10.1111/j.1467-9922.2012.00704.x

Sparks, R., \& Ganschow, L. (1993). The Impact of Native Language Learning Problems on Foreign Language Learning: Case Study Illustrations of the Linguistic Coding Deficit Hypothesis. The Modern Language Journal, 77(1), 58-74. https://doi.org/10.2307/329559

Sparks, R., \& Ganschow, L. (2007). Is the Foreign Language Classroom Anxiety Scale measuring anxiety or language skills? Foreign Language Annals, 40, 260-87.

Sparks, R. L., Patton, J., Ganschow, L., Humbach, N., \& Javorsky, J. (2008). Early first-language reading and spelling skills predict later second-language reading and spelling skills. Journal of Educational Psychology, 100(1), 162-174. https://doi.org/10.1037/0022-0663.100.1.162

Sparks, R., Patton, J., Ganschow, L., \& Humbach, N. (2009). Long-term relationships among early first language skills, second language aptitude, second language affect, and later second language proficiency. Applied Psycholinguistics, 30(4), 725-755. https://doi.org/10.1017/S0142716409990099

Sprenger-Charolles, L., Colé, P., Béchennec, D., \& Kipffer-Piquard, A. (2005). French normative data on reading and related skills from EVALEC, a new computerized battery of tests (end Grade 1, Grade 2, Grade 3, and Grade 4) [Lecture et compétences reliées: Données normatives pour la fin de la 1re, 2nde, $3 \mathrm{e}$ et $4 \mathrm{e}$ année du primaire issues d'une nouvelle batterie de tests, EVALEC]. European Review of Applied Psychology / Revue Européenne de Psychologie Appliquée, 55(3), 157-186. https://doi.org/10.1016/j.erap.2004.11.002

Sprenger-Charolles, L., Colé, P., \& Serniclaes, W. (2006). Reading acquisition and developmental dyslexia. Hove, UK : Psychology Press.

Sprenger-Charolles, L., Colé, P., Piquard-Kipffer, A., \& Leloup, G. (2010). Batterie informatisée d'évaluation diagnostique des troubles spécifiques d'apprentissage de la lecture (EVALEC). Ortho Edition.

Sun-Alperin, M. K., \& Wang, M. (2009). Cross-Language Transfer of Phonological and Orthographic Processing Skills in Spanish-Speaking Children Learning to Read and Spell in English. Reading and Writing: An Interdisciplinary Journal, 24, 591-614.

Toothaker, L (1993). Multiple Comparison Procedures. Newbury Park: Sage Publications, Inc. https://doi.org/10.4135/9781412985178

Vellutino, F. R., Fletcher, J. M., Snowling, M. J, \& Scanlon, D. M. (2004). Specific reading 


\section{Al Macrothink}

Education and Linguistics Research

ISSN 2377-1356 2018, Vol. 4, No. 1

disability (dyslexia): what have we learned in the past four decades? Journal of Child Psychology and Psychiatry, 45, 2-40.

Wade-Woolley, L., \& Geva, E. (2000). Processing Novel Phonemic Contrasts in the Acquisition of L2 Word Reading. Scientific Studies of Reading, 4, 295-311. https://doi.org/10.1207/S1532799XSSR0404_3

Wimmer, H., \& Landerl, K. (1997). How learning to spell German differs from learning to spell English. In C. A. Perfetti, L. Rieben, \& M. Fayol (Eds), Learning to Spell: Research, Theory and Practice across Languages (pp. 81-96). New Jersey: Erlbaum.

Ziegler, J. C., \& Goswami, U. (2005). Reading Acquisition, Developmental Dyslexia, and Skilled Reading across Languages: A Psycholinguistic Grain Size Theory. Psychological Bulletin, 131, 3-29. https://doi.org/10.1037/0033-2909.131.1.3

Ziegler, J. C., Bertrand, D., Toth, D., Csépe, V., Reis, A., Faísca, L., Saine, N., Lyytinen, H., Vaessen, A., \& Blomert, L. (2010). Orthographic depth and its impact on universal predictors of reading: A cross-language investigation. Psychological Science, 21, 551-559. https://doi.org/10.1177/0956797610363406

\section{Copyright Disclaimer}

Copyright reserved by the author(s).

This article is an open-access article distributed under the terms and conditions of the Creative Commons Attribution license (http://creativecommons.org/licenses/by/3.0/). 